\title{
Extraperitoneal Inguinoscrotal Herniation of the Ureter: A Rare Case of Recurrence after Hernia Repair
}

\author{
E. Golgor ${ }^{a} \quad$ C. Stroszczynski ${ }^{a} \quad$ M. Froehner ${ }^{b}$ \\ anstitute of Diagnostic Radiology and ${ }^{\mathrm{b}}$ Department of Urology, University Hospital Carl Gustav Carus, \\ Technical University Dresden, Dresden, Germany
}

\section{Key Words}

Inguinoscrotal herniation - Extraperitoneal inguinoscrotal hernia $\cdot$ Computed tomography $\cdot$ Ureteral obstruction

\begin{abstract}
Inguinoscrotal herniation of the ureter is a rare finding with the potential for serious surgical complications. Two anatomic forms are defined. In the more common paraperitoneal variant, the herniating peritoneal sac drags the ureter and sometimes other abdominal structures with it. The uncommon variant - extraperitoneal inguinal hernia - is without a peritoneal sac and consists of the ureter and fat tissue. We report a case of extraperitoneal inguinoscrotal hernia possibly due to a prior inguinal hernia repair.
\end{abstract}

Copyright $\odot 2009$ S. Karger AG, Basel

\section{Introduction}

Herniation of the ureter outside the abdominal cavity is uncommon. While case reports of thoracic, sciatic and crural herniation exist, the most frequently described location is herniation into the inguinoscrotal region [1]. Even a very few cases of intermittent inguinal herniation have been reported [2]. Awareness of this possibility helps to avoid iatrogenic injuries to the ureter and other retroperitoneal structures at the time of hernia repair.

We report a case of an unexpected finding of inguinoscrotal hernia of the ureter, most likely a result of prior hernia repair 18 years ago.

\section{Case Report}

A 68-year-old man presented with a 5-day history of constipation and dysuria. He had a past history of a left-sided inguinal hernia repair 18 years ago, as well as hypertension, coronary artery disease and obesity. Abdominal ultrasound showed a leftsided hydronephrosis. His white blood cell count was $13.4 \times$ $10^{9} / \mathrm{l}$, and C-reactive protein was $6.8 \mathrm{mg} / \mathrm{l}$.

A contrast-enhanced computed tomography (CT) was performed, which confirmed the left-sided hydronephrosis and revealed herniation of the left ureter into the scrotum (fig. la, b). Other causes of extrinsic ureteral obstruction, e.g. venous anomalies [3], were excluded. Dilated small bowel loops suggesting subileus were also seen. Further diagnostic tests, including retrograde urethrography (fig. 1c) underlining CT diagnosis of inguinoscrotal herniation, were undertaken.

Surgery was performed to relieve the ureteral obstruction, which was felt to be the cause of the ipsilateral hydronephrosis. Intraoperatively, extraperitoneally herniated ureter was repositioned intraabdominally and the hernia was repaired. Finally, the resection of approximately $20 \mathrm{~cm}$ of an extremely elongated and widened ureter was performed.

\section{KARGER}

Fax +4161306 1234

E-Mail karger@karger.ch

www.karger.com
(C) 2009 S. Karger AG, Basel

0042-1138/09/0831-0113\$26.00/0

Accessible online at:

www.karger.com/uin
Elena Golgor

Institute of Diagnostic Radiology, University Hospital Carl Gustav Carus Technical University Dresden, Fetscherstrasse 74, DE-01307 Dresden (Germany) Tel. +49 3514582 259, Fax +49351 4584321

E-Mail elena.golgor@uniklinikum-dresden.de 
Fig. 1. Two dilated ureteral branches inside the scrotum. a Axial CT image. b Maximum intensity project reconstruction. c Urographic findings.
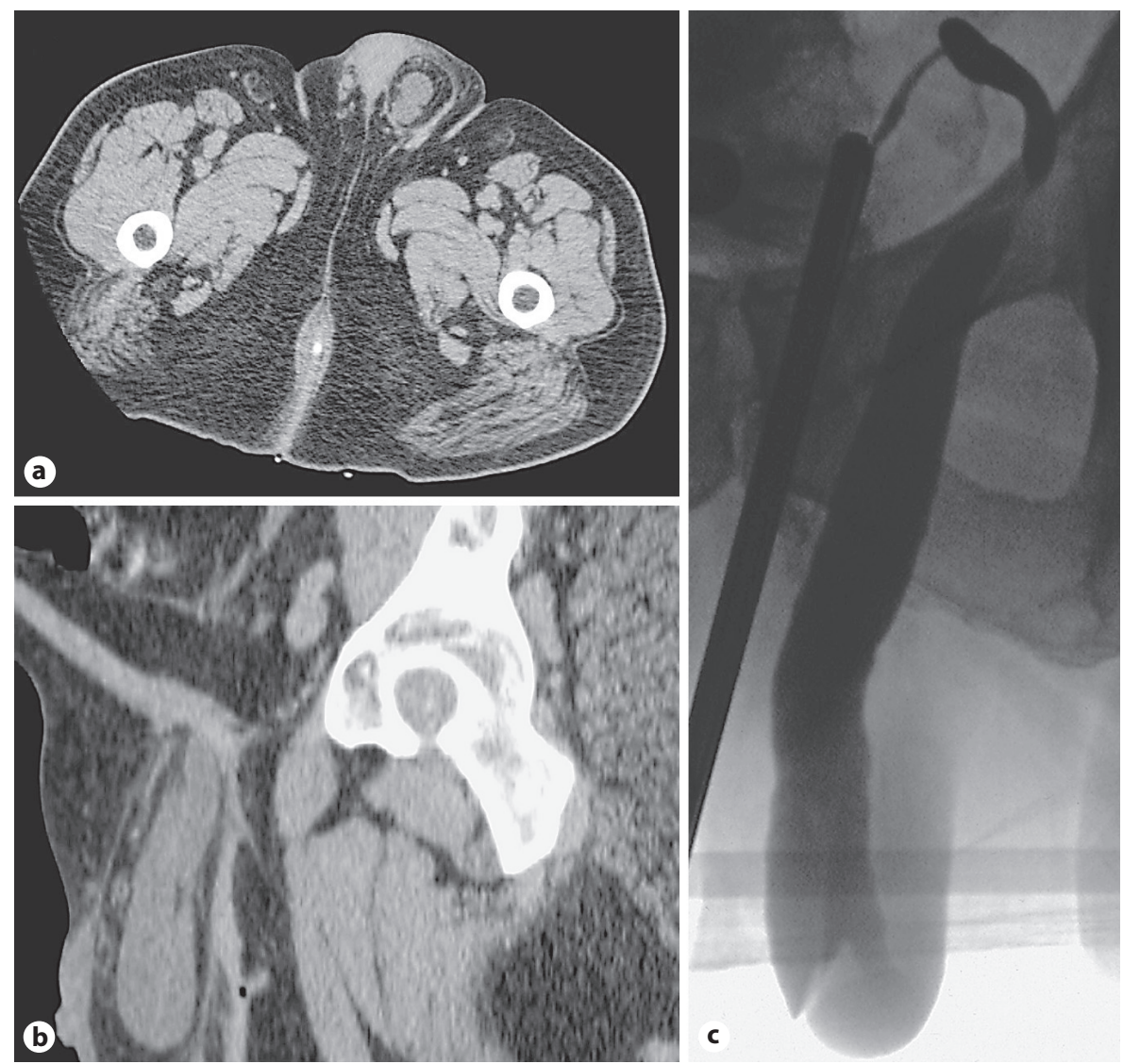

\section{Discussion}

Ureteral herniation is a rare phenomenon. The first report was an autopsy case published by Leroux in 1880 [4]. In 2003, Giuly et al. [5] collated and summarized 60 cases with ureter involved in inguinoscrotal herniation. To obtain recent studies we performed a systematic MEDLINE and Google review of English-language publications from April 2003 till September 2007. A total of 5 isolated cases of ureteral inguinoscrotal herniation in patients with non-transplant kidneys were identified [6-10].

Most reported cases of ureteral herniation have been observed in obese male patients during their fifth or sixth decade of life. Ureteral hernias are predominantly indirect [8]. The classification of ureteral hernias depends upon the presence or absence of a concomitant hernial sac. The more frequent paraperitoneal variant is associated with a hernial sac [11]. It is a sliding hernia and can consist of the ureter alone, though more frequently other abdominal organs such as the bladder and bowel are within the sac [5]. In the rare extraperitoneal type, a peri- toneal sac is not present and the ureter is the only structure that herniates. In these cases there is usually a large amount of accompanying fat tissue. Anomalies of the renal tract have been described with this type of herniation [9].

Our report describes a case of inguinoscrotal herniation of the ureter, probably a result of hernia repair 18 years earlier. We believe that this is the first reported case of a ureteral hernia occurring as part of a hernia recurrence. It could be qualified as an extraperitoneal type as just the ureter was the herniated structure.

Whilst it is difficult to determine the etiology for ureteral herniation, we suggest that the previous hernia repair surgery could have caused the development of adhesions between the ureter and the peritoneum by pulling the ureter into the scrotum. It is also possible that herniation of the ureter resulted from a developmental ureteral abnormality, but as the patient had neither a previously documented congenital genitourinary malformation nor genitourinary symptoms, this suggestion seems less likely. 
Most patients with ureteral herniation are asymptomatic [1], with detection occurring at the time of surgery [4]. However, several cases have been identified, as occurred in this case, by CT, with subsequent confirmation on delayed post-contrast $3 \mathrm{D}$ reconstruction images. For the few patients who have specific urologic symptoms such as dysuria or frequency, the performance of preop- erative excretory urography is recommended [11], at which time the upper urinary tract should be checked for any possible anomalies. Therefore, direct and multiplanar multislice CT images of adjacent anatomic structures can be helpful for planning therapy. Even in the absence of clinical symptoms, surgical interference is indicated in all cases of inguinal hernia of the ureter [5].

\section{References}

1 Eilber KS, Freedland SJ, Rajfer J: Obstructive uropathy secondary to ureteroinguinal herniation. Rev Urol 2001;3:207-208.

2 Remmele WM, Prikler L, Schmid HP, Engeler DS: Intermittent ureteral herniation rare cause of flank pain. Urol Int 2006;77: 286-288.

3 Huwyler M, Willmann JK, John H: Functional ureteral obstruction due to complex pelvic venous anomaly. Urol Int 2007;79: 284-286.

4 Mallouh C, Pellman CM: Scrotal herniation of the ureter. J Urol 1971;106:38-41.
5 Giuly J, Francois GF, Giuly D, Leroux C, Nguyen-Cat RR: Intrascrotal hernia of the ureter and fatty hernia. Hernia 2003;7:4749.

6 Mantle M, Kingsnorth AN: An unusual cause of back pain in an achondroplastic man. Hernia 2003;7:95-96.

7 Akpinar E, Turkbey B, Ozcan O, Akdogan B, Karcaaltincaba M, Ozen H: Bilateral scrotal extraperitoneal herniation of ureters: computed tomography urographic findings and review of the literature. J Comput Assist Tomogr 2005;29:790-792.

8 Bertolaccini L, Giacomelli G, Bozzo RE, Gastaldi L, Moroni M: Inguinoscrotal hernia of a double district ureter: case report and literature review. Hernia 2005;9:291-293.
9 Roach SC, Moulding F, Hanbidge A: Inguinal herniation of the ureter. AJR Am J Roentgenol 2005; 185:283.

10 Brand ME, Brooks S, Brooks-Searle K, Ester RM Jr: Ureteroinguinal hernia: a rare cause of ureteral obstruction. Surg Rounds 2006; 29:128-133.

11 Giglio M, Medica M, Germinale F, Raggio M, Campodonico F, Stubinski R, Carmignani G: Scrotal extraperitoneal hernia of the ureter: case report and literature review. Urol Int 2001;66:166-168. 